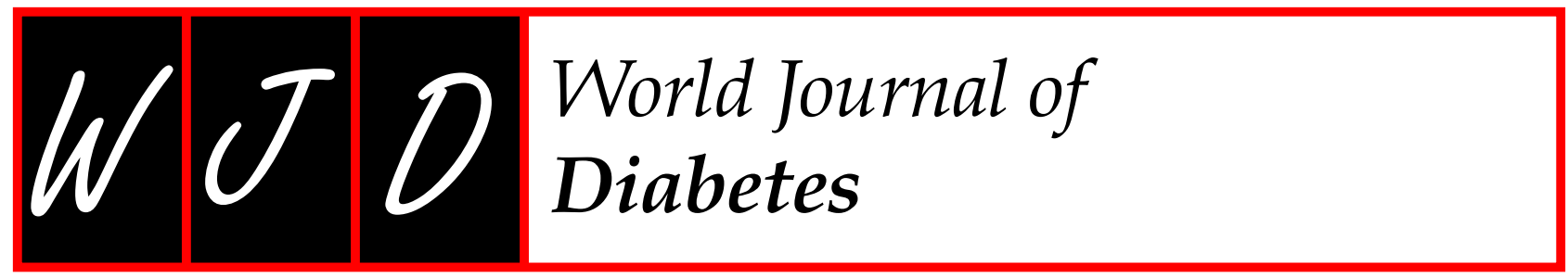

Online Submissions: http:/ / www.wjgnet.com/esps/ wjd@wjgnet.com

doi:10.4239/wjd.v3.i12.182

World J Diabetes 2012 December 15; 3(12): 182-185

(C) 2012 Baishideng. All rights reserved.

FIELD OF VISION

\title{
Management of type 2 diabetes mellitus in youth
}

\author{
Vassilios Giampatzis, Konstantinos Tziomalos
}

Vassilios Giampatzis, Konstantinos Tziomalos, First Propedeutic Department of Internal Medicine, Medical School, Aristotle University of Thessaloniki, AHEPA Hospital, 54636 Thessaloniki, Greece

Author contributions: Giampatzis V drafted the paper; Tziomalos $\mathrm{K}$ revised the draft critically for important intellectual content.

Correspondence to: Konstantinos Tziomalos, MD, PhD, First Propedeutic Department of Internal Medicine, Medical School, Aristotle University of Thessaloniki, AHEPA Hospital, 54636 Thessaloniki, Greece. ktziomalos@yahoo.com Telephone: +30-2310-994621 Fax: +30-2310-994773

Received: August 8, 2012 Revised: November 8, 2012

Accepted: November 17, 2012

Published online: December 15, 2012

\begin{abstract}
The rising rates of obesity in youth have concurrently led to an increase in the rates of type 2 diabetes mellitus (T2DM) in this age group. However, there are limited data on the efficacy of different antidiabetic agents in youth. In this context, the Treatment Options for Type 2 Diabetes in Adolescents and Youth trial recently reported that the majority of obese children and adolescents 10-17-years old with newly diagnosed T2DM (T2DM duration less than 2 years) could not achieve HbA1c levels $<8 \%$ for more than 1 year with metformin monotherapy, metformin plus rosiglitazone combination, or metformin and lifestyle changes. These findings suggest that, in the majority of youth with T2DM, tight long-term glycemic control with oral agents is an elusive goal and that most patients will require treatment with insulin within a few years of diagnosis to achieve HbA1c targets and reduce the risk of macroand microvascular complications. Therefore, reducing the incidence of T2DM by preventing pediatric obesity through the implementation of lifestyle changes in the community should be the primary objective of healthcare systems.
\end{abstract}

(C) 2012 Baishideng. All rights reserved.
Key words: Type 2 diabetes mellitus; Metformin; Rosiglitazone; Lifestyle changes; Insulin

Peer reviewers: Dr. Sule Apikoglu-Rabus, Associate Professor, Clinical Pharmacy Department, Marmara University Faculty of Pharmacy, Tibbiye Cd, 34668, Haydarpasa, Istanbul, Turkey; Juan Carlos Laguna, PhD, Pharmacology Department, Faculty of Pharmacy and Institute of Biomedicine (IBUB), University of Barcelona, 08028 Barcelona, Spain; Mohamed A Haidara, PhD, Department of Physiology, Kasr Al-Aini Faculty of Medicine, Cairo University, Giza, Egypt; Moses S Elisaf, MD, PhD, FASA, FRSH, Department of Internal Medicine, Medical School, University of Ioannina, 45110 Ioannina, Greece; Dr. Surajit Nayak, Department of Skin and VD, MKCG Medical College and Hospital, Berhampur 760004, Orissa, India

Giampatzis V, Tziomalos K. Management of type 2 diabetes mellitus in youth. World J Diabetes 2012; 3(12): 182-185 Available from: URL: http://www.wjgnet.com/1948-9358/full/ v3/i12/182.htm DOI: http://dx.doi.org/10.4239/wjd.v3.i12.182

\section{INVITED COMMENTARY ON HOT}

\section{ARTICLES}

Obesity is becoming increasingly prevalent in children and adolescents, putting considerable burden on public healthcare services ${ }^{[1,2]}$. According to the 2007-2010 National Health and Nutrition Examination Survey data, $16.9 \%$ of 6 - to 19 -year-old in the United States are obese ${ }^{[2]}$. These rising rates of obesity in youth have concurrently led to an increase in the rates of type 2 diabetes mellitus (T2DM) in this age group ${ }^{[3]}$. The overall prevalence of T2DM in youth is 0.22 cases per $1000^{[4]}$ and it is estimated that T2DM accounts for $15 \%$ to $86 \%$ of newly diagnosed cases of diabetes mellitus in ages 10-19 years with the higher prevalence rates reported among ethnic minorities ${ }^{[5]}$.

Despite the increasing rates of T2DM in youth, there are limited data on the efficacy of different antidiabetic agents in this age group. Furthermore, additional dif- 
ficulties emerge during the treatment of this special population, including the psychological and emotional changes of adolescence as well as particularities of the specific familial and socioeconomic environment ${ }^{[6,7]}$.

In this context, the Treatment Options for Type 2 Diabetes in Adolescents and Youth (TODAY) trial provides new insights on the management of this understudied group of patients ${ }^{[8]}$. This multicenter study included children and adolescents 10- to 17-year-old who had T2DM for less than 2 years (mean T2DM duration $7.8 \mathrm{mo}$ ) and body mass index (BMI) $\geqslant$ the 85th percentile for age and sex. Of the 1211 subjects who were screened, 927 patients entered a run-in phase during which metformin was administered at a dose of 1000-2000 mg/d to achieve HbA1c levels < 8\%. At the end of the run-in period, 699 patients were randomly assigned to continue metformin monotherapy at a dose of $1000 \mathrm{mg}$ twice daily, to receive metformin and rosiglitazone $4 \mathrm{mg} / \mathrm{d}$ combination treatment, or to receive metformin and lifestyle intervention focusing on weight loss through family-based changes in eating and activity behaviors. The primary endpoint was treatment failure, defined as HbA1c levels persistently $\geqslant 8 \%$ over a 6 -mo period or persistent metabolic decompensation (i.e., inability to discontinue insulin within 3 mo after its initiation for decompensation or recurrent decompensation within 3 mo of stopping insulin). Patients were followedup for a mean of 3.86 years.

Treatment failure occurred in $51.7 \%$ of patients in the metformin monotherapy group (95\% CI 45.3-58.2), in $38.6 \%$ of patients treated with metformin plus rosiglitazone combination (95\% CI 32.4-44.9), and in 46.6\% of patients managed with metformin and lifestyle modification $(95 \% \text { CI } 40.2-53 \cdot 0)^{[8]}$. Metformin plus rosiglitazone treatment reduced the occurrence of treatment failure by $25.3 \%$ compared with metformin monotherapy $(P=0.006)$. Treatment failure rates did not differ significantly between patients treated with metformin combined with lifestyle intervention and patients treated with either metformin monotherapy or metformin combined with rosiglitazone. The median time to treatment failure was $11.5 \mathrm{mo}$ (range, $<1$ to $66 \mathrm{mo}$ ) and did not differ between the 3 groups. The BMI increased significantly more in patients treated with metformin plus rosiglitazone than in the other groups. The group that received metformin and lifestyle intervention exhibited less BMI increase than patients treated with metformin monotherapy. However, neither BMI at baseline nor BMI during treatment predicted treatment failure. Adherence to treatment was 57\% at month 60 and did not differ between the 3 groups. Changes in blood pressure and lipids were also comparable in the 3 groups. Serious adverse events were reported by $18.1 \%, 14.6 \%$ and $24.8 \%$ of patients treated with metformin alone, metformin plus rosiglitazone, and metformin plus lifestyle intervention, respectively $(P=0.02)$. The most frequent adverse effects in all groups were infections, gastrointestinal symptoms, rash, muscle ache and elevation of liver enzymes.

Until now, metformin and glimepiride are the only oral agents approved by the Food and Drug Administration for the treatment of children with $\mathrm{T} 2 \mathrm{DM}^{[9]}$. Although metformin is recommended as first-line treatment in this age group ${ }^{[10]}$, the TODAY study showed that in children and adolescents who have T2DM for $<$ 2 years, metformin maintains optimal glycemic status in $<50 \%$ of patients after 1 year. When metformin monotherapy does not achieve HbA1c targets, sulphonylureas are the most frequently added oral agents ${ }^{[10]}$. However, sulphonylureas are associated with weight gain and increase the risk for hypoglycemia ${ }^{[11]}$. Unfortunately, the TODAY study did not include a sulphonylurea arm and the benefit/risk ratio of metformin plus sulphonylurea combination in this age group remains unclear. Nevertheless, in adults with newly diagnosed T2DM, sulphonylurea monotherapy maintains HbA1c targets after 3 years in $<50 \%$ of patients ${ }^{[12]}$. On the other hand, in adults, rosiglitazone monotherapy appears to be associated with more sustained glycemic control than monotherapy with either metformin or sulphonylureas ${ }^{[13]}$. Nevertheless, rosiglitazone has been withdrawn from Europe and its use is restricted in the United States because it appears to increase the risk for myocardial infarction ${ }^{[14]}$. Pioglitazone, the other member of the thiazolidinediones class, does not appear to increase cardiovascular risk $^{[15]}$, but both agents are associated with weight gain, edema and increased risk for heart failure and fractures $^{[11]}$. Moreover, pioglitazone was recently withdrawn from France because of increased risk for bladder cancer $^{[16,17]}$. In addition to these safety concerns, almost $40 \%$ of patients treated with metformin plus rosiglitazone combination in the TODAY study could not maintain HbA1c levels $<8 \%$ after 1 year. Therefore, the efficacy of adding rosiglitazone in this age group also appears to be suboptimal. It should also be emphasized that treatment failure rates did not differ in the TODAY study between patients treated with metformin plus rosiglitazone and patients given metformin and lifestyle advice.

Overall, the findings of the TODAY study suggest that, in order to achieve optimal glycemic control, the majority of children and adolescents with T2DM will require treatment with insulin within a few years after diagnosis ${ }^{[8]}$. Even though insulin can achieve sustained normalization of HbA1c levels, it has the drawbacks of weight gain and elevated risk of hypoglycemic episodes $^{[11,18]}$. In addition, the parenteral administration of insulin is an important barrier for the introduction of this treatment ${ }^{[19]}$. Moreover, the need in some cases for multiple daily injections to optimize glycemic control hampers the intensification of insulin treatment ${ }^{[19]}$. Common misperceptions of patients regarding insulin, including the belief that it represents failure of oral agents or a sign of uncontrolled diabetes with a higher risk for long-term complications, are additional obstacles for initiating insulin ${ }^{[20]}$. In addition, after the introduction of insulin, adherence is lower than those with oral 
antidiabetic agents ${ }^{[19]}$. The issue of adherence to treatment is particularly pertinent to adolescents ${ }^{[18]}$. Indeed, in the TODAY study, only $57.6 \%$ of patients adhered to treatment with oral antidiabetic agents ${ }^{[8]}$. Moreover, satisfaction with antidiabetic treatment, which is directly correlated with adherence, is lower in patients treated with insulin than in those who receive oral agents ${ }^{[2]}$.

In conclusion, the findings of the TODAY study suggest that, in the majority of youth with T2DM, tight glycemic control is an elusive goal with oral agents even in the context of a clinical trial involving presumably motivated patients. Therefore, achieving HbA1c goals will probably be even more difficult in everyday clinical practice. It remains to be established whether newer antidiabetic agents, particularly dipeptidyl-peptidase IV (DPP-IV) inhibitors and glucagon-like peptide 1 (GLP-1) analogues, will provide more sustained glycemic control in adolescents with T2DM. These agents have the advantage that they either not cause weight gain (the DPP-IV inhibitors) or induce weight loss (the GLP-1 analogues) and are considered second line treatment in adult diabetic patients who cannot achieve glycemic targets with metformin monotherapy ${ }^{[21]}$. However, they are not currently licensed for use in patients younger than 18 years. Accordingly, reducing the incidence of T2DM by preventing pediatric obesity through lifestyle changes should be the primary objective of healthcare systems. Randomized trials in adults showed that diet and exercise reduces the risk of T2DM in patients with impaired fasting glucose or impaired glucose tolerance ${ }^{[22,23]}$. However, long-term adherence to lifestyle changes is difficult to achieve, particularly in adolescents, as shown in the TODAY and other studies ${ }^{[8,24]}$. Therefore, implementing healthcare policies to address causes of low adherence to lifestyle modifications, including low socioeconomic and educational status, limited health care accessibility and family problems ${ }^{[25,26]}$, are imperative to prevent the development of obesity and T2DM in children and adolescents.

\section{REFERENCES}

1 Hedley AA, Ogden CL, Johnson CL, Carroll MD, Curtin LR, Flegal KM. Prevalence of overweight and obesity among US children, adolescents, and adults, 1999-2002. JAMA 2004; 291: $2847-2850$

2 Ogden CL, Carroll MD, Kit BK, Flegal KM. Prevalence of obesity and trends in body mass index among US children and adolescents, 1999-2010. JAMA 2012; 307: 483-490

3 Hannon TS, Rao G, Arslanian SA. Childhood obesity and type 2 diabetes mellitus. Pediatrics 2005; 116: 473-480

4 Liese AD, D'Agostino RB, Hamman RF, Kilgo PD, Lawrence JM, Liu LL, Loots B, Linder B, Marcovina S, Rodriguez B, Standiford D, Williams DE. The burden of diabetes mellitus among US youth: prevalence estimates from the SEARCH for Diabetes in Youth Study. Pediatrics 2006; 118: 1510-1518

5 Dabelea D, Bell RA, D'Agostino RB, Imperatore G, Johansen JM, Linder B, Liu LL, Loots B, Marcovina S, MayerDavis EJ, Pettitt DJ, Waitzfelder B. Incidence of diabetes in youth in the United States. JAMA 2007; 297: 2716-2724

6 Copeland KC, Zeitler P, Geffner M, Guandalini C, Higgins
J, Hirst K, Kaufman FR, Linder B, Marcovina S, McGuigan P, Pyle L, Tamborlane W, Willi S. Characteristics of adolescents and youth with recent-onset type 2 diabetes: the TODAY cohort at baseline. J Clin Endocrinol Metab 2011; 96: 159-167

7 Zeitler P, Epstein L, Grey M, Hirst K, Kaufman F, Tamborlane W, Wilfley D. Treatment options for type 2 diabetes in adolescents and youth: a study of the comparative efficacy of metformin alone or in combination with rosiglitazone or lifestyle intervention in adolescents with type 2 diabetes. Pediatr Diabetes 2007; 8: 74-87

8 Zeitler P, Hirst K, Pyle L, Linder B, Copeland K, Arslanian S, Cuttler L, Nathan DM, Tollefsen S, Wilfley D, Kaufman F. A clinical trial to maintain glycemic control in youth with type 2 diabetes. N Engl J Med 2012; 366: 2247-2256

9 Rodbard HW. Diabetes screening, diagnosis, and therapy in pediatric patients with type 2 diabetes. Medscape J Med 2008; 10: 184

10 Type 2 diabetes in children and adolescents. American Diabetes Association. Diabetes Care 2000; 23: 381-389

11 Bennett WL, Maruthur NM, Singh S, Segal JB, Wilson LM, Chatterjee R, Marinopoulos SS, Puhan MA, Ranasinghe P, Block L, Nicholson WK, Hutfless S, Bass EB, Bolen S. Comparative effectiveness and safety of medications for type 2 diabetes: an update including new drugs and 2-drug combinations. Ann Intern Med 2011; 154: 602-613

12 Turner RC, Cull CA, Frighi V, Holman RR. Glycemic control with diet, sulfonylurea, metformin, or insulin in patients with type 2 diabetes mellitus: progressive requirement for multiple therapies (UKPDS 49). UK Prospective Diabetes Study (UKPDS) Group. JAMA 1999; 281: 2005-2012

13 Kahn SE, Haffner SM, Heise MA, Herman WH, Holman RR, Jones NP, Kravitz BG, Lachin JM, O'Neill MC, Zinman B, Viberti G. Glycemic durability of rosiglitazone, metformin, or glyburide monotherapy. $N$ Engl J Med 2006; 355: 2427-2443

14 Nissen SE, Wolski K. Rosiglitazone revisited: an updated meta-analysis of risk for myocardial infarction and cardiovascular mortality. Arch Intern Med 2010; 170: 1191-1201

15 Dormandy JA, Charbonnel B, Eckland DJ, Erdmann E, Massi-Benedetti M, Moules IK, Skene AM, Tan MH, Lefèbvre PJ, Murray GD, Standl E, Wilcox RG, Wilhelmsen L, Betteridge J, Birkeland K, Golay A, Heine RJ, Korányi L, Laakso M, Mokán M, Norkus A, Pirags V, Podar T, Scheen A, Scherbaum W, Schernthaner G, Schmitz O, Skrha J, Smith $\mathrm{U}$, Taton J. Secondary prevention of macrovascular events in patients with type 2 diabetes in the PROactive Study (PROspective pioglitAzone Clinical Trial In macroVascular Events): a randomised controlled trial. Lancet 2005; 366: 1279-1289

16 Available from: URL: http: //ansm.sante.fr/Activites/ Surveillance-des-medicaments/Medicaments-retires-dumarche/Medicaments-suspendus-retires-du-marche-ou-encours-d-arret-depuis-janvier-2011/ACTOS/(language)/freFR (Accessed July 13, 2012)

17 Colmers IN, Bowker SL, Majumdar SR, Johnson JA. Use of thiazolidinediones and the risk of bladder cancer among people with type 2 diabetes: a meta-analysis. CMAJ 2012; 184: E675-E683

18 Flint A, Arslanian S. Treatment of type 2 diabetes in youth. Diabetes Care 2011; 34 Suppl 2: S177-S183

19 Cramer JA. A systematic review of adherence with medications for diabetes. Diabetes Care 2004; 27: 1218-1224

20 Biderman A, Noff E, Harris SB, Friedman N, Levy A. Treatment satisfaction of diabetic patients: what are the contributing factors? Fam Pract 2009; 26: 102-108

21 Inzucchi SE, Bergenstal RM, Buse JB, Diamant M, Ferrannini E, Nauck M, Peters AL, Tsapas A, Wender R, Matthews DR. Management of hyperglycaemia in type 2 diabetes: a patient-centered approach. Position statement of the Ameri- 
can Diabetes Association (ADA) and the European Association for the Study of Diabetes (EASD). Diabetologia 2012; 55: 1577-1596

22 Knowler WC, Barrett-Connor E, Fowler SE, Hamman RF, Lachin JM, Walker EA, Nathan DM. Reduction in the incidence of type 2 diabetes with lifestyle intervention or metformin. N Engl J Med 2002; 346: 393-403

23 Tuomilehto J, Lindström J, Eriksson JG, Valle TT, Hämäläinen H, Ilanne-Parikka P, Keinänen-Kiukaanniemi S, Laakso M, Louheranta A, Rastas M, Salminen V, Uusitupa M. Prevention of type 2 diabetes mellitus by changes in lifestyle among subjects with impaired glucose tolerance. $N$ Engl J Med 2001; 344: 1343-1350
24 Rothman RL, Mulvaney S, Elasy TA, VanderWoude A, Gebretsadik T, Shintani A, Potter A, Russell WE, Schlundt D. Self-management behaviors, racial disparities, and glycemic control among adolescents with type 2 diabetes. Pediatrics 2008; 121: e912-e919

25 Tiv M, Viel JF, Mauny F, Eschwège E, Weill A, Fournier C, Fagot-Campagna A, Penfornis A. Medication adherence in type 2 diabetes: the ENTRED study 2007, a French Population-Based Study. PLoS One 2012; 7: e32412

26 Lindström J, Absetz P, Hemiö K, Peltomäki P, Peltonen $\mathrm{M}$. Reducing the risk of type 2 diabetes with nutrition and physical activity - efficacy and implementation of lifestyle interventions in Finland. Public Health Nutr 2010; 13: 993-999

S- Editor Wen LL L- Editor A E- Editor Xiong L 